\title{
A Comparative study of Wear and tool life of HSS TiN coated end mills and WC uncoated end mills.
}

\author{
Praphan Yawara ${ }^{1, a}$ and Naphatara Intanon ${ }^{1}$ \\ ${ }^{1}$ Faculty of Technical Education, Rajamangala University of Technology Isan Khon Kaen Campus, Khon Kaen, Thailand
}

\begin{abstract}
The objective of this research is to compare the performance and economic value of TiN coated end mills and WC end mills on S45C slot milling. The commercial end mills that produce and provide by SAN Engineering and Supply Co., Ltd. and commercial S45C steels, were selected for this investigation. The models of wear were analyzed by the scanning electron microscope, SEM. The result showed that the wear models of the TiN coated end mills are abrasive and surface peeling, while the wear models of WC end mills are adhesive and uniform micro-chipping on the cutting edges. The analysis the economic value also represented that $\mathrm{WC}$ end mills are worth more than the others.
\end{abstract}

\section{Introduction}

A small and medium manufacture companies have an importance for manufacturing industries of Thailand. The cutting tools are an important part of the production process and represent a significant share in the costs of manufactured products. An evaluation of the operation process such as material tools and time is an important task which is one of the ways to reduce production costs.

In general, Tungsten carbide (WC) end mills were used for a machine carbon steel, and performs better at high speed level than High-Speed Steel (HSS) end mills, even though, the price of $\mathrm{WC}$ is relatively high. The Physical vapor deposition (PVD) is a coating technique that can improve a cutting performance and tool life of the tools [1]. The most common material that used to a coating to improve mechanical properties of the surface is Titanium. The workpiece that coated by titanium is used in the machine tools industry, automotive part and in the medical [2-4]. The TiN is wildly coated materials since it has the advantages properties include high hardness and adhesion, good ductility, excellent lubricity, high chemical stability and tough resistance to wear [5]. The wear of coated cutting tools has been analyzed by several researchers [6]. However, most of researchers are being studied in the extreme case such as high-speed milling, specific material or specific machine part. Due to the price of the coating process is very expensive and is wildly used in the laboratory. Thus, WC is mostly used in the area of SME industries even it costs more, however, it significantly shows an economic value better than a TiN coated end mills. Moreover, in recently the price of coated tools decreased to a possible level for the uses in industrial. Therefore, the SME should start to reconsider on the price and performance of coated tools for effective use again.

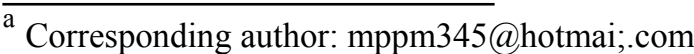

This research is conducted in order to compare the performance and economy of TiN coated end mills and WC end mills to find a way of tools selection for Thailand SME.

\section{Material and Methods}

\subsection{Work piece material and cutting tools}

The materials of all experiments were the commercial S45C steels. (Chemical component in weight \% : C 0.42$0.48, \mathrm{Mn} 0.60-0.90, \mathrm{P} 0.03, \mathrm{~S} 0.035$, Si 0.15-0.35 Hardness 160-220 HB). There were two types of end mills used in this study. The first one is a TiN coated HSS end mills and the other one is WC end mills. Both of materials was supported by SAN Engineering and Supply Co.,Ltd

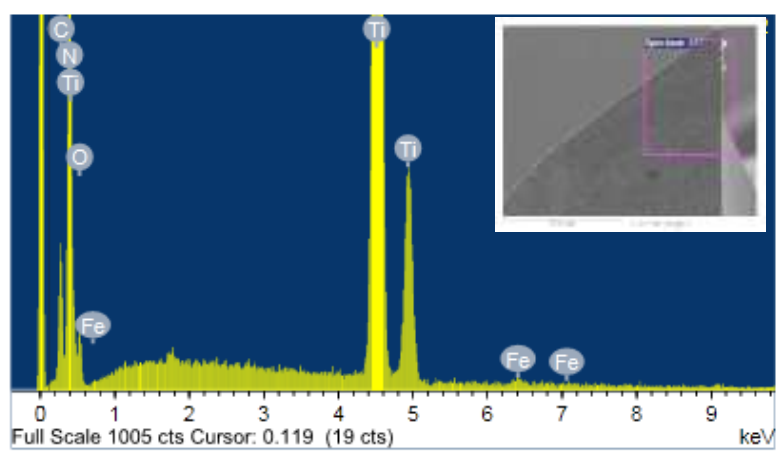

Figure1 Spectrum of TiN coated HSS end mill surface.

Table 1 shows the chemical composition of the TiN coated end mills surface. The atomic ratio of $\mathrm{Ti}$ and $\mathrm{N}$ is $25.89: 43.86$ or 1:1.69 while the typical TiN formation had roughly $1: 1$. 
Table1. Chemical composition of TiN coated HSS end mills

\begin{tabular}{|c|l|c|c|c|c|}
\hline Element & $\mathbf{C}$ & $\mathbf{N}$ & $\mathbf{O}$ & $\mathbf{T i}$ & $\mathbf{F e}$ \\
\hline $\begin{array}{c}\text { Weight } \\
\text { \% }\end{array}$ & 7.30 & 26.84 & 11.31 & 54.17 & 0.38 \\
\hline $\begin{array}{c}\text { Atomic } \\
\%\end{array}$ & 13.91 & 43.86 & 16.18 & 25.89 & 0.15 \\
\hline
\end{tabular}

The mechanical properties, especially the hardness, of the coated surface are upon the atomic ratio of $\mathrm{Ti}$ and $\mathrm{N}$ [7-8]. The atomic ratio of Ti : $\mathrm{N}$ of TiN coated HSS end mills was $1: 1.69$, it had a higher than normal range value and the hardness of the coating surface is $1236.7 \mathrm{HV}$, lower than the general hardness of TiN about $30 \%$. However, the variation of $\mathrm{Ti}: \mathrm{N}$ ratio is a function of temperature [9] and therefore the hexagonal $\alpha$-Ti phase could dissolve up to 15 atomic \% nitrogen. [10].

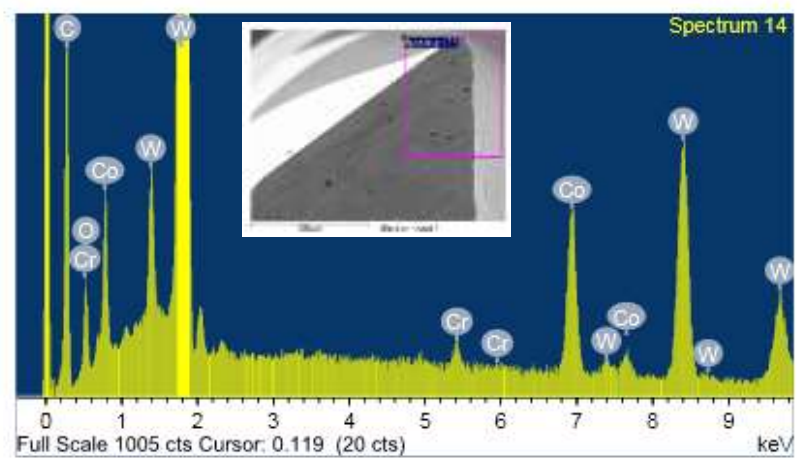

Figure2 Spectrum of WC end mills.

Table 2. Chemical composition of WC end mill.

\begin{tabular}{|c|l|c|c|c|c|}
\hline Element & $\mathbf{C}$ & $\mathbf{C r}$ & $\mathbf{O}$ & $\mathbf{C o}$ & $\mathbf{W}$ \\
\hline $\begin{array}{c}\text { Weight } \\
\mathbf{\%}\end{array}$ & 25.05 & 0.70 & 4.62 & 8.54 & 61.09 \\
\hline $\begin{array}{c}\text { Atomic } \\
\mathbf{\%}\end{array}$ & 72.89 & 0.47 & 10.07 & 5.06 & 11.60 \\
\hline
\end{tabular}

Table 2 showed that the atomic \% ratio of $\mathrm{W}$ : $\mathrm{C}$ on WC end mills is 11.60: 72.89 or 1:6.28. The atomic ratio of typical WC was 1: 1, although the ratio of $\mathrm{W}$ : $\mathrm{C}$ was exchanged when added other materials depending to the manufacturer. In this case, the manufacturer added the cobalt $(\mathrm{Co})$ into the chemical composition in order to increase the mechanical properties of the end mills.

\subsection{Cutting parameters and procedure}

Milling experiment was carried out under dry (nonlubricant) and wet (with lubricant) condition by using a Maike BSC 800 CNC millings machine. The optimization of cutting parameter, cutting speed $\left(V_{c}\right)$ and feed per teeth $(f z)$, for TiN coated HSS end mills on slot milling with a lubricant condition were $35-45 \mathrm{~m} . / \mathrm{min}$. and $0.05-0.06 \mathrm{~mm}$./teeth, respectively. And for the same condition recommended were $60-100 \mathrm{~m} . / \mathrm{min}$ and $0.02-$ $0.04 \mathrm{~mm} /$ teeth for $V c$ and $F z$, respectively [11].

$$
\text { Spindle Speed }=\frac{1000 \times V_{C}}{\pi D}
$$

For TiN coated HSS $(V c=40 \mathrm{~m} . / \mathrm{min})$

$$
\text { Spindle speed }=\frac{1000 \times 40}{\pi 12}=1,061 \mathrm{rev} \text {. per min }
$$

For $\mathrm{WC}\left(V_{c}=80 \mathrm{~m} . / \mathrm{min}\right)$

$$
\text { Spindle speed }=\frac{1000 \times 80}{\pi 12}=2,122 \text { rev. per min }
$$

However, this investigation has an economic comparison and parameters which used for the comparison are operation price and time (tool life). The operation time is upon the feed rate $(v f)$. The equation of feed rate is $v f=f_{z} \cdot z \cdot n$ therefore, feed rate of TiN coated HSS end mills is $0.05 \cdot 4 \cdot 1061=212.2 \mathrm{~mm} . / \mathrm{min}$. and feed rate of WC end mills is $0.03 \cdot 4 \cdot 2122=254.64$ $\mathrm{mm} . / \mathrm{min}$. Overall, the machine parameter of investigation can be show in table3.

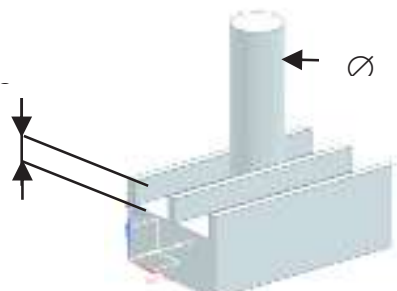

Figure3. Slot milling diagram

Table3. Machine Parameter

\begin{tabular}{|l|l|l|}
\hline Work material & \multicolumn{2}{|c|}{ S45C } \\
\hline Axial depth of cut & $\mathrm{mm}$ & 6 \\
\hline Radial depth of cut & $\mathrm{mm}$ & 12 \\
\hline $\begin{array}{l}\text { Feed }\left(f_{Z}\right) \text { (TiN coated HSS } \\
\text { end mills) }\end{array}$ & $\mathrm{mm} /$ tooth & 0.05 \\
\hline Feed $\left(f_{z}\right)$ (WC end mills) & $\mathrm{mm} /$ tooth & 0.03 \\
\hline $\begin{array}{l}\text { Feed rate (TiN coated HSS } \\
\text { end mills) }\end{array}$ & $\mathrm{min} . / \mathrm{min}$. & 212 \\
\hline Feed rate (WC end mills) & $\mathrm{min} . / \mathrm{min}$. & 255 \\
\hline $\begin{array}{l}\text { Spindle speed (TiN coated } \\
\text { HSS end mills) }\end{array}$ & rev./min & 1061 \\
\hline Spindle speed (WC end mills) & rev./min & 2122 \\
\hline
\end{tabular}

The trial was two times repeated for each cutting condition in order to maintain the minimum error data. After finished in each condition, an end mills were cleaned and dried before diameter measurement. The measurement was taken two times follow a flute of end mills and average diameter value were recorded. The measurement tool of this research is a $0.001 \mathrm{~mm}$. $(0.0005$ inch) digital micrometer (Mitutoyo) 


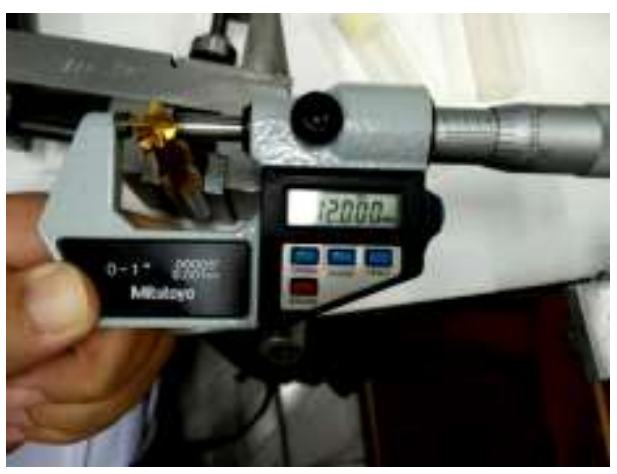

Figure4. Diameter measurement

\section{Results}

\subsection{Wear and wear behavior}

Table 4. and Figure 5. showed that the average of loss of TiN coated HSS end mills diameter after used in dry condition is $.046 \mathrm{~mm}$. and the average loss diameter of TiN coated HSS end mills in wet condition is $.045 \mathrm{~mm}$. and the average of loss of WC end mills in dry and wet condition are .0425 and .012 respectively. The diameter loss of TiN coated HSS end mills in both conditions are barely different, but it is rather different on WC end mills. Because of the wear mechanism of WC end mills in wet condition is an adhesive wear that lower wear rate than an abrasive wear in the dry condition. While the wear mechanism of TiN coated HSS end mills in the wet condition is micro-chipping that high wear rate as same as an abrasive wear that it is a wear mechanism of TiN coated HSS end mills in dry condition.

Table 4. Size of end mills

\begin{tabular}{|l|c|c|c|c|}
\hline \multirow{2}{*}{ Type of end mills } & \multicolumn{2}{|c|}{ Before (mm.) } & \multicolumn{2}{c|}{ After (mm.) } \\
\cline { 2 - 5 } & No.1 & No.2 & No.1 & No.2 \\
\hline TiN coated (dry) & 12.001 & 12.001 & 11.954 & 11.956 \\
\hline TiN coated(wet) & 12.001 & 12.002 & 11.957 & 11.956 \\
\hline WC (dry) & 12.001 & 12.002 & 11.958 & 11.960 \\
\hline WC(wet) & 12.002 & 12.002 & 11.991 & 11.989 \\
\hline
\end{tabular}

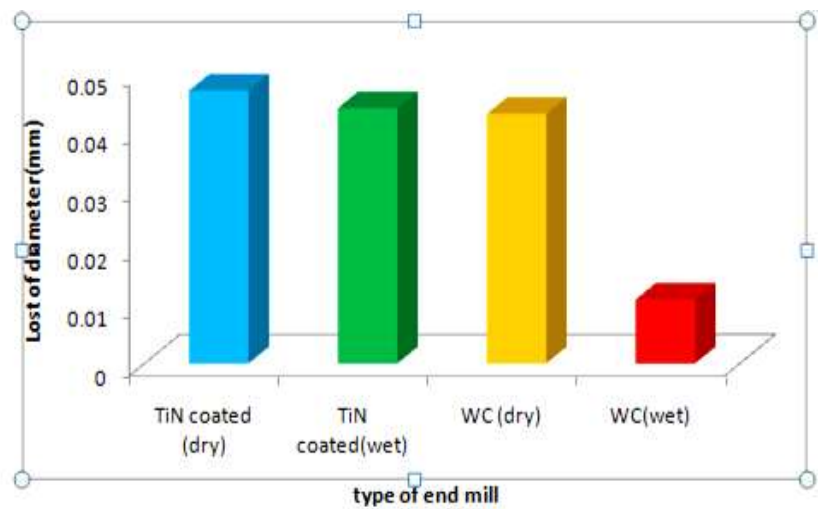

Figure5. Loss of diameter of end mills

The tool wear observed in the investigation is very specific. According to the optical and metallographic observation of wear behavior on the cutting edges could be established into two types of wear occurred in most cases: flank wear micro-chipping.

The initial observation of the wear behavior of both end mills on dry condition found that the rake surface was abrasive. The tool material (included coating material) loss from the tool flank which is normality of constant and extend over range of contact between tool and work piece. In wet condition, wear behavior was difference from dry condition. The rake surface of WC end mills was polished while the rake surface of TiN coated HSS end mills was not polished, but it showed non-uniform chipping $(\mathrm{CH} 2)$. However, in the same condition (dry or wet) the machine parameter of tools was different, especially the spindle speed and feed rate.

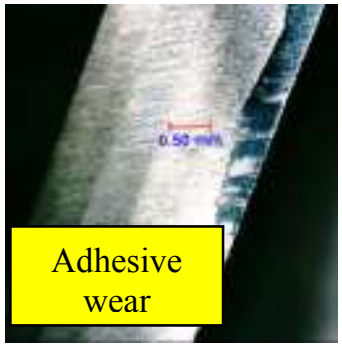

(a)

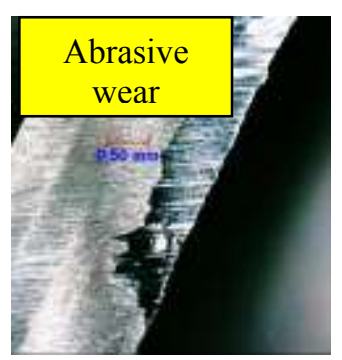

(b)
Figure6. The rake face of WC end mills (50X) (a) wet condition (b) dry condition

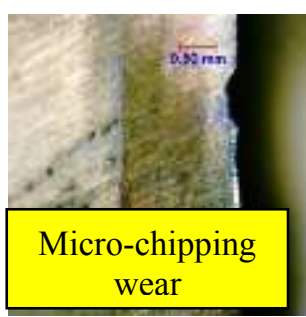

(a)

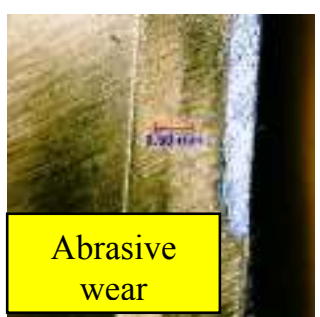

(b)
Figure7. The rake face of TiN coated HSS end mills (50X) (a) wet condition (b) dry condition

In general, early stage of the tool wear was adhesive wear mechanical and next step is abrasive mechanical. However, it is difficult to separate due to most of wear were a combination of many mechanical.

To get a better insight into the wear behavior of cutting tools for all cutting edges, SEM was taken. The SEM images of TiN coated HSS end mills after milling is presented in figure 8.(a-d). The peeling of coating surface is prominent on dry condition (Figure.8(a-c)), conversely, on wet condition the peeling was decreased but the micro-chipping of the cutting edge was higher than a dry condition.

Figure 9. showed that the wear models for dry condition of WC end mills are uniform micro-chipping on the cutting edges (Figure 9. (a-c)). For the wet 
condition, the wear models of is micro-chipping and abrasive wear (Figure 9. d).

\subsection{Economic analysis}

Tool life is a span of actual machining time by which a new tool can work until the wear of tool reaches a limit point. In general, limit point of end mills is flank wear, the recommended uniform flank wear is $0.3 \mathrm{~mm}$. Form table 1. If the wear rate of end mills constants, the length of the slot of the TiN coated HSS can make in a dry condition as $3.26 \mathrm{~m}$. and the length of the slot that the other end mills can make could be $3.33 \mathrm{~m}, 3.53 \mathrm{~m}$ and $12.5 \mathrm{~m}$. for TiN coated HSS end mills in wet condition, WC end mills in dry condition and WC in wet condition, respectively. The price of end mills that used in this investigation are THB $1450(\$ 44)$ for TiN coated HSS end mills and THB 1650(\$50) for WC end mills. The cost of end mills per meters of the slot is THB 444.67, THB 435, THB 467.6 and THB 132 respectively. The highest cost is WC end mills in dry condition; likewise, the lowest cost is WC end mills in wet condition.

\section{Discussion}

The wear behaviors of end mills are widely published. Sometime theoretically propounded findings were greater benefits to the manufacturers that could be the users of the tools. [8] In this study, the selected end mills were the commercials. The user's knowledge about the chemical composition of tools has limited. The user knows only that the main composition of tools which is the name of the type of tools and main composition of WC end mills is WC. In fact, WC end mills have many compositions and with some elements when is added into, it might change the hole properties. The WC end mills that used in this investigation has no common composition, the atomic $\%$ of $\mathrm{W}$ is low. But, it showed the higher performance than a TiN coated HSS end mills.

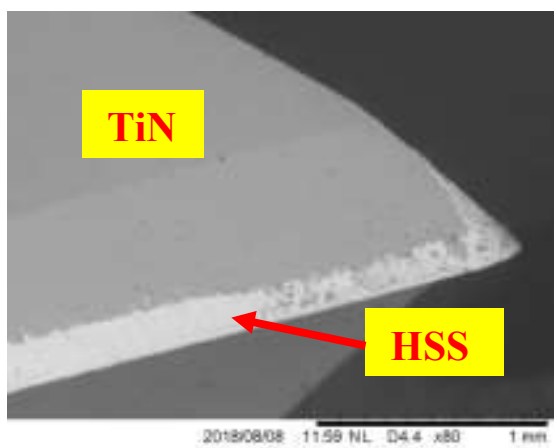

a.

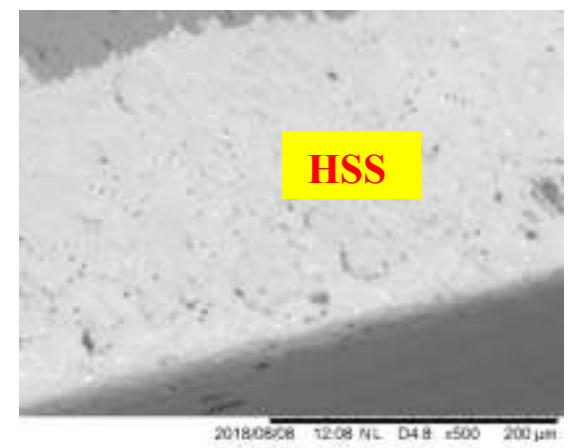

b.

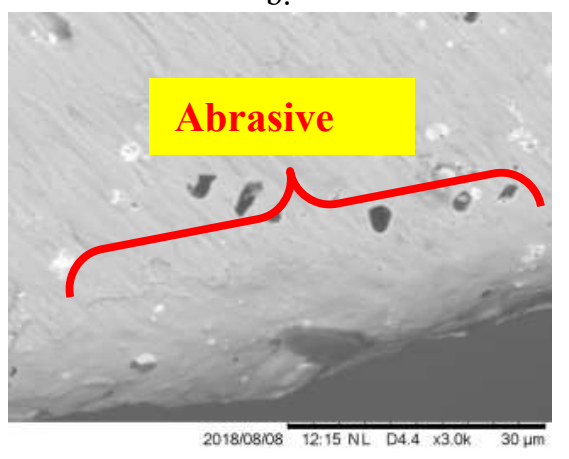

c

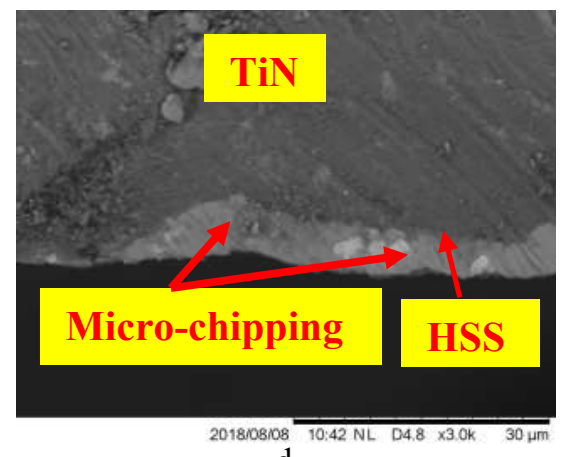

d.

Figure8. Cutting edge of TiN coated HSSend mills

(a) 90X, (b)500X, (c)3000X (d) 3000X (wet)

However, it is not used to compare with the other WC end mills. So, the result could not be explained that it is better or worse than the other WC end mills that have a common composition. As same as, TiN coated surface has no common composition, but it showed a better wear resistant when used with lubricant.

In dry condition, the diameter of WC end mills and TiN coated HSS end mills after millings are almost equal. Because the TiN coated HSS end mills have a coated surface that high resistance and $\mathrm{WC}$ end mills was sensitive to the high temperature. Although, TiN has a high wear resistance, but after the coated surface peeling the wear, it will start and rapidly increase due to the wear rate of TiN coated HSS end mills is higher than the others. The contact area between tools and work piece in the slot mailing process are higher than end milling process and type of cutting is up cut are a good catalysts for peeling process. It is a main reason of high peeling of coated surface. In wet condition, the peeling of the coated surface was lower but the micro-chipping is greater than it, caused of the diameter after millings are almost equal. According to Sokovic,M. et,al. claimed that the coated end mills have no place in dry cutting. [11] As same as, WC end mills, the abrasive wear is lower but the microchipping wear is high. So, the loss of diameter is almost equal to the TiN coated HSS end mills and it is more different when compare to the end mills on wet condition.

The cost of tools is a main effect to the competitive advantage of SEM. This investigation shows that the best appropriate tool is $\mathrm{WC}$ end mill while the worst appropriate tool is also WC end mill, as well. (High price) It was upon the machine condition. Actually, the 
main jobs of SME was generally used steels, except the specific products that used a cast iron. So, the machine process was used with the lubricant and WC end mills should be selected. However, most of SEM orders are a job shop that the quantity of job is about $10-20$ pieces. If the tools life is longer than the working time, the longer tools life (higher price) does not necessary. For example, from this investigation, working life of TiN coated end mills is $3.33 \mathrm{~m}$. and $12.5 \mathrm{~m}$. for WC end mills. If all of working distant of some job are $3.0 \mathrm{~m}$., the SMEs should select the TiN coated end mills, but if they predict that they will make this job again in the next month, then WC end mills should be a good choice to be selected.
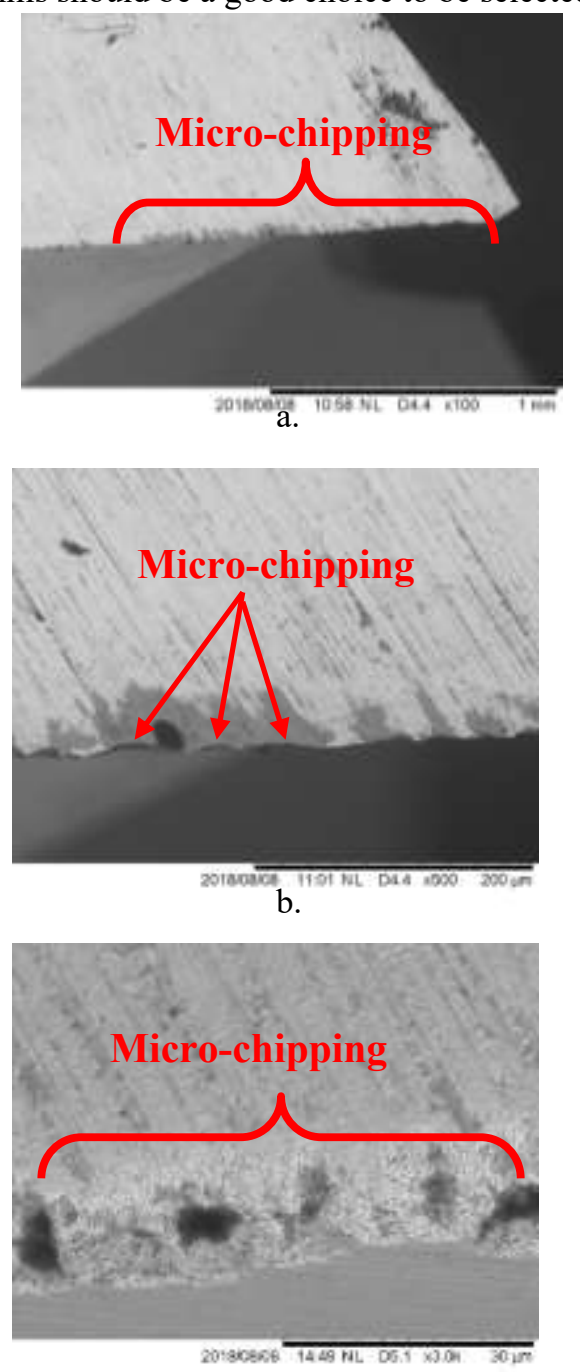

C

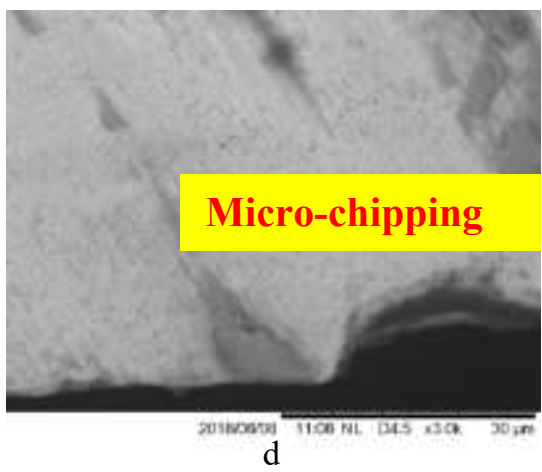

Figure 9. Cutting edge of WC end mills (a) 100X (b) $500 X(3) 3000 X(d) 3000 X$ (wet)

\section{Conclusion}

This investigation shows that the wear of end mills depending on the base material and machining parameters. According to the research of Sokovic, M. et, al. founded that the coated high-speed cutting tools showed quite different wear behavior depending on the base material used, type of coating and machining parameters [12]. The WC end mills has the advantage in wet condition even though it has high abrasion resistant and can also withstand higher temperatures. However, in the dry condition, TiN which was a ceramic material, it could perform better. Thus, the WC end mills is not appropriate in dry condition since without lubricant the temperature is high and might effect to wear mechanical of WC.

The economic value analysis found that $\mathrm{WC}$ is optimal for the wet condition but in dry condition should be used a TiN coated HSS end mills. Since the TiN coated surface has a good wear resistance and WC has higher hardness and it is a cause of micro-chipping in high-temperature.

\section{Acknowledgements}

This research was supported by The Faculty of Technical Education, Rajamangala University of Technology Isan campus, Khon Kaen. Thailand.

\section{References}

1. T. L. Banh, Q. T. Phan and D. B. Nguyen, ATM, 6[2], 244 (2004)

2. Y. Tamura, A. Yokoyama, F. Watari, M. Uo and T. Kawasaki, Mat.Trans., 43(12), 3043 (2002)

3. D. Martinez-Martinez, C. Lopez-Cartes, A. Fernandez, J.C. Sanchez-Lope, Appl. Surf. Sci., 275, 121 (2013)

4. X.H. Zheng, J.P. Tu, B. Gu, S.B. Hu, Wear 265, 261 (2008)

5. W. Yanfeng, L. Zhenxian, W. Haonan, D. Jihong, Z. Changwei, Rare Metal Materials and Engineering, 46(5) 1219 (2017)

6. C.Y. Wang, Y.X. Xie, Z. Qin, H.S. Lin, Y.H. Yuan, Q.M. Wang, Wear 336-337 29 (2015)

7. J. Hoon Kang, K. Joo Kim, J. of Appl. Phys. 86, 346 (1999).

8. U.W. Bläß, T. Barsukova, M.R. Schwarz, A. Köhlera, C. Schimpf, I.A. Petrusha, U. Mühle, D. Rafaja, E. Kroke, J. of the Euro. Cera. Society 35, 2733 (2015)

9. K. Vasua, M. Ghanashyam Krishnaa K.A. Padmanabhan, Appl. Surf. Sci. 257, 3069 (2011)

10. B. Subramanian, K. Ashok, M. Jayachandran, Appl. Surf. Sci. 255, 2133 (2008)

11. Uddeholm corrax. Cutting data recommendations. www.uddeholm.com/files/Cutting_Data_Corrax_eng, (2007)

12. M. Sokovic, J. Kopac, L.A. Dobrzanski, M. Adamiak, J. Mater. Process Technol.157-158, 422. (2004) 